\title{
PERENCANAAN SISTEM OPERASIONAL ANGKUTAN WISATA DI KOTA DENPASAR
}

Dyah Ayu Lesatri ${ }^{1}$, P. Alit Suthanaya ${ }^{2}$, D.M. Priyantha Wedagama. ${ }^{2}$

\begin{abstract}
Abstrak: Pariwisata merupakan sektor utama bagi perekonomian di Bali. Kota Denpasar sebagai Ibu Kota Provinsi Bali diharapkan mampu mempertahankan posisi sebagai salah satu destinasi wisata unggulan dengan meningkatkan dan memperbaiki fasilitas pariwisata yang ada, dan salah satunya dengan pengadaan angkutan wisata yang melayani wisatawan menuju ke objek wisata yang ada di Kota Denpasar. Penelitian ini bertujuan untuk menganalisis potensi demand, rute angkutan wisata serta sistem karakteristik operasional angkutan wisata di Kota Denpasar. Dari analisis yang telah dilakukan, diperoleh potensi demand angkutan wisata di Kota Denpasar adalah 438.576 orang pada tahun 2013 dan diperkirakan menjadi 485.998 pada tahun 2017. Jumlah kunjungan tertinggi wisatawan ke objek wisata adalah dengan rute : Prasasti Blanjong, Pulau Serangan, Balai Pengelolaan Hutan Mangrove, Desa Budaya Kertalangu, Taman Budaya Art Center, Museum Lukisan Sidik Jari, Monumen Bajra Sandhi, Pasar Kumbasari, Pasar Badung, Museum Bali. Alternatif paket wisata meliputi wisata reguler 10 objek wisata, reguler city tour, reguler wisata alam, charter city tour, dan charter wisata alam. Angkutan wisata beroperasi menggunakan bus sedang dan minibus dengan waktu pelayanan 8 jam dari pukul 09.00 s/d 17.00 wita untuk reguler dan 4,5 jam-5,5 jam untuk paket charter. Headway ditetapkan 30 menit.
\end{abstract}

Kata kunci: angkutan wisata, potensi demand, sistem operasional

\section{PLANNING OPERATIONAL SYSTEM TOURISM TRANSPORT IN DENPASAR CITY}

\begin{abstract}
Tourism is the main sector for the economy of Bali. Denpasar City as the capital city of Bali Province is expected to maintain its position as one of main tourist destinations by increasing and improving existing tourism facilities, and one of them with the provision of tourism transport that serving tourists heading into tourism attraction in the city of Denpasar. The purposes of this research are to analyze the potential demand, tourism transport route and the characteristic of operational system of tourism transport in Denpasar City. From the analysis that has been done, it is obtained that the potential demand of tourist transport in Denpasar City is 438.576 people in 2013 and it is estimated to be 485.998 in 2017. The highest number of tourist those visit the attraction places through the routes of : Belanjong Pillar, Serangan Island, Central Management of Mangrove Forest, The Village of Budaya Kertalangu, Taman Budaya Art Centre, Museum Painting Fingerprint, Bajra Sandhi Monument, Kumbasari Market, Badung Market, Bali Museum. Alternatives tour packages include regular tour packages with 10 attractions, regular city tours, regular nature tours, city tour charters, and natural attraction charters. Tourist transports operate using medium buses and minibus for 8 hours service time from 09.00 am until $17.00 \mathrm{pm}$ for regular and 4,5 hours until 5,5 hours for charter package. The headway is set 30 minutes.
\end{abstract}

Keywords: tourism transport, potential demand,operational system

\footnotetext{
${ }^{1}$ Mahasiswa Program Magister Teknik Sipil, Fakultas Teknik, Universitas Udayana, Denpasar

${ }^{2}$ Staf Pengajar Program Magister Teknik Sipil, Fakultas Teknik, Universitas Udayana, Denpasar
} 


\section{PENDAHULUAN}

Selain sebagai Ibukota dari Provinsi Bali, Kota Denpasar yang terdiri dari empat kecamatan yaitu Denpasar Barat, Denpasar Timur, Denpasar Utara dan Denpasar Selatan memiliki tempattempat wisata yang menarik yang sering dikunjungi oleh wisatawan domestik maupun asing seperti Pasar Seni Kumbasari, Museum Bali, Taman Budaya Art Center, Monumen Bajra Sandhi serta Pantai Sanur. Jumlah wisatawan yang berkunjung ke Kota Denpasar pada tahun 2013 untuk wisatawan domestik 258.813 orang dan wisatawan asing sejumlah 184.962 orang dengan total kunjungan 443.775 orang (Disparda Provinsi Bali, 2014).

Menurut data Direktori Kepariwisataan Denpasar tahun 2014, jumlah biro perjalanan wisata di Denpasar Selatan sebanyak 94 usaha, Denpasar Timur sebanyak 41 usaha, Denpasar Barat sebanyak 37 usaha, dan jumlah biro perjalanan di Denpasar Utara sebanyak 4 usaha. Dengan banyaknya usaha yang bergerak di bidang pariwisata, maka banyak pula terjadi pergerakan angkutan wisata yang memiliki kontribusi terhadap permasalahan transportasi yang ada di Kota Denpasar. Pada saat ini wisatawan sering memilih untuk menyewa mobil (rentcar) maupun menyewa motor dikarenakan mudahnya mendapatkan kendaraan sewa, serta lebih efisien dalam mobilitasnya.

Saat ini banyak bus pariwisata yang berukuran besar, melayani wisatawan untuk mengunjungi objek-objek wisata yang ada di Kota Denpasar. Dengan meningkatnya jumlah kunjungan wisatawan diperlukan penyediaan angkutan wisata city tour, selain untuk meningkatkan fasilitas pariwisata di Kota Denpasar juga dapat meningkatkan pendapatan Kota Denpasar dan menambah lapangan kerja bagi penduduk Kota Denpasar. Angkutan shuttle bus service city tour pernah diterapkan,di Kota Denpasar namun belum memberikan hasil yang optimal. Kelemahannya antara lain pada sistem operasional seperti rute yang belum optimal. Shuttle bus service Denpasar city tour hanya digunakan pada saat berlangsungnya acara pesta kesenian Bali dan pada hari-hari tertentu saja. Untuk membantu dalam menanggulangi permasalahan transportasi di Kota Denpasar sebagai daerah tujuan wisata, penelitian ini dilakukan untuk mengkaji ulang sistem operasional angkutan wisata yang diperuntukkan bagi wisatawan di Kota Denpasar. Saat ini belum diketahui potensi demand dan rute yang harus dilalui serta sistem operasional angkutan wisata yang dapat diterapkan di Kota Denpasar. Sehingga penelitian ini bertujuan untuk:
1. menganalisis potensi demand dan rute angkutan wisata yang dapat dikembangkan di Kota Denpasar

2. untuk menganalisis sistem karakteristik operasional angkutan wisata yang dapat diterapkan di Kota Denpasar.

\section{PERENCANAAN ANGKUTAN WISATA}

Menurut Undang Undang No. 10/2009 tentang Kepariwisataan, yang dimaksud dengan pariwisata adalah berbagai macam kegiatan wisata yang didukung oleh berbagai fasilitas serta layanan yang disediakan masyarakat, pengusaha, Pemerintah dan Pemerintah Daerah.

Pengertian objek wisata menurut Peraturan Pemerintah Republik Indonesia No. 24/1979 adalah perwujudan dari pada ciptaan manusia, tata hidup, seni budaya, serta sejarah bangsa atau keadaan alam yang mempunyai daya tarik wisata bagi wisatawan untuk dikunjungi, sedangkan daya tarik atau atraksi wisata adalah semua yang diciptakan manusia berupa penyajian kebudayaan tari-tarian, kesenian rakyat, upacara adat, dan lain-lain.

Dalam mengembangkan objek wisata, pemerintah melakukan berbagai usaha perbaikan di bidang prasarana dengan membangun dan mengadakan rehabilitasi terhadap akses jalan menuju daerah tujuan wisata. Misalnya penataan kawasan geografis yang berada di wilayah Sanur atau Pulau Serangan guna menarik kunjungan wisatawan. Objek wisata maupun daya tarik wisata adalah dua hal yang paling mendasar dalam pengembangan di bidang pariwisata.

\section{Angkutan Wisata}

UU No.22 Tahun 2009 tentang lalu lintas dan angkutan jalan menjelaskan salah satu tujuan diselenggarakannya lalu lintas dan angkutan jalan, yaitu untuk mewujudkan pelayanan lalu lintas dan angkutan jalan yang aman, selamat, tertib, lancar, dan terpadu dengan moda angkutan lain untuk mendorong perekonomian nasional, memajukan kesejahteraan umum, memperkukuh persatuan dan kesatuan bangsa, serta mampu menjunjung tinggi martabat bangsa. Angkutan wisata merupakan angkutan umum yang bertujuan khusus untuk mengangkut wisatawan tidak dalam trayek.

Pelayanan angkutan pariwisata diselenggarakan dengan ciri-ciri sebagai berikut (Kepmen No. 35, Tahun 2003):

a. Mengangkut wisatawan atau rombongan

b. Pelayanan angkutan dari dan ke daerah tujuan wisata atau tempat lainnya

c. Dilayani dengan bus

d. Tidak masuk terminal 


\section{Sistem Operasional Angkutan Wisata}

Perencanaan sistem operasional angkutan wisata di Kota Denpasar mengacu pada standar perhitungan angkutan kota, dimana analisis operasional angkutannya meliputi : waktu siklus, headway, dan perhitungan kebutuhan armada (Departemen, 1996).

a. Perhitungan waktu siklus

$$
\begin{aligned}
\mathrm{CT}_{\mathrm{ABA}}= & \left(\mathrm{T}_{\mathrm{AB}}+\mathrm{T}_{\mathrm{BA}}\right)+\left(\sigma_{\mathrm{AB}}{ }^{2}+\sigma_{\mathrm{BA}}{ }^{2}\right)+ \\
& \left(\mathrm{T}_{\mathrm{TA}}+\mathrm{T}_{\mathrm{TB}}\right)
\end{aligned}
$$

Keterangan :

CTABA $=$ Waktu sirkulasi dari A ke B, kembali ke A

$\mathrm{TAB}=$ Waktu perjalanan rata-rata dari $\mathrm{A}$ ke $\mathrm{B}$

TBA = Waktu perjalanan rata-rata dari $\mathrm{B}$ ke $\mathrm{A}$

$\sigma \mathrm{AB}=$ Deviasi waktu perjalanan rata-rata dari $\mathrm{A}$ ke B

$\sigma \mathrm{BA}=$ Deviasi waktu perjalanan rata-rata dari $\mathrm{B}$ ke A

TTA $=$ Waktu henti kendaraan di terminal A

TTB $=$ Waktu henti kendaraan di terminal $\mathrm{B}$

b. Perhitungan headway

Nilai headway diaumsikan 30 menit dengan memperhitungkan kemacetan di dalam Kota Denpasar.

c. Perhitungan kebutuhan armada

$$
\text { Lf }=\frac{\mathrm{Jp}}{\mathrm{C}} \times 100 \%
$$

Keterangan :

$\mathrm{Jk}=$ Jumlah kendaraan yang dibutuhkan

$\mathrm{CT}=$ Waktu sirkulasi (menit)

$\mathrm{H}$ = Headway / waktu antara kendaraan angkutan Kota (menit)

$\mathrm{FA}=$ Faktor ketersediaan kendaraan angkutan kota $(\%)$

\section{METODE}

\section{Pengumpulan Data}

Pada penelitian ini dilakukan pengumpulan data dengan menggunakan data sekunder maupun data primer. Data primer didapat langsung pada objek penelitian, adapun cara dalam mendapatkan data primer dengan mewancarai showroom kendaraan dan bengkel suku cadang untuk mengetahui data harga terkini tahun 2015. Selain itu data primer jua didapat dari survey yang dilakukan langsung oleh peneliti untuk mendapatkan data perjalanan, waktu dan rute.

Data sekunder merupakan data yang didapat dari sumber terkait yang nantinya data tersebut dapat langsung digunakan dalam analisis oleh peneliti. Data sekunder pada penelitian ini didapat dari instansi terkait mengenai peta jaringan jalan, pariwisata, dan lain sebagainya.

\section{Rancangan Penelitian}

Rancangan penelitian merupakan kerangka kegiatan yang mencakup semua perincian yang berhubungan dengan rencana penelitian.

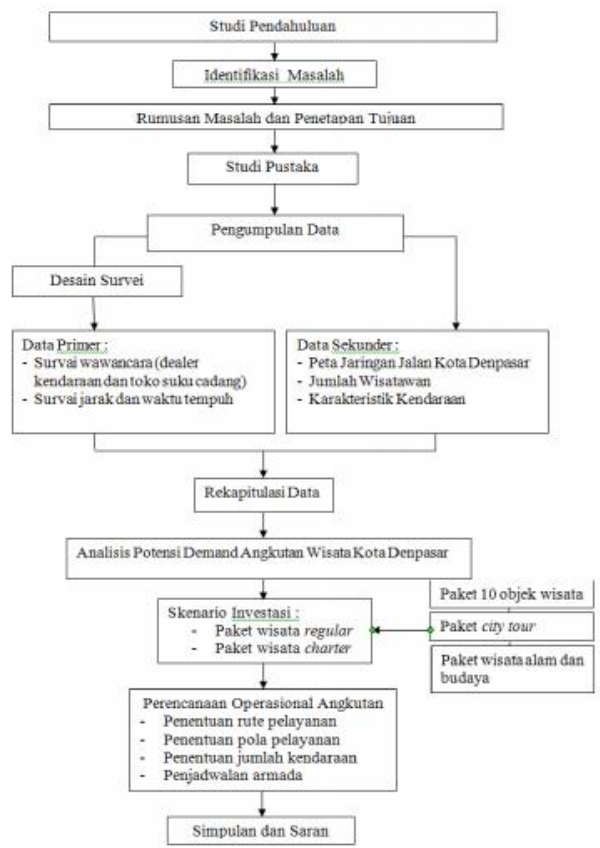

Gambar 1. Diagram Alir Rancangan Penelitian

\section{Lokasi Penelitian}

Lokasi pada penelitian ini adalah kawasan pariwisata Kota Denpasar yang terdiri dari 4 kecamatan, baik Denpasar Utara, Denpasara Selatan, Denpasar Timur serta Denpasar Barat, dimana pada kawasan tersebut sering mengalami kemacetan, dimana salah satu penyebabnya adalah karena kegiatan pariwisata.

\section{Analisis Potensi Demand Angkutan Wisata dan Rute Perjalanan}

Potensi penumpang (demand) wisatawan yang beralih menggunakan angkutan wisata dalam penelitian ini menggunakan jumlah wisatawan yang didapat pada data sekunder dari instansi Kepariwisataan terkait. Data jumlah pariwisata yang diambil menggunakan jumlah kunjungan wisatawan kunjungan objek tertinggi pada tahun 2009 sampai dengan tahun 2013, kemudian dilakukan estimasi ke tahun rencana pada tahun 2017 dengan asumsi 30\% dari total kunjungan wisatawan merupakan potensi demand (wisatawan yang beralih menggunakan angkutan wisata city tour). Selanjutnya ditentukan lintasan atau rute layanan angkutan wisata sesuai dengan lokasi objek wisata dengan data kunjungan tertinggi tiap tahunnya. Adapun pemilihan lintasan dikelompokkan sesuai dengan daya tarik tiap objek wisata kedalam paket wisata. 


\section{Skenario Investasi}

Umur rencana pada penelitian ini menggunakan umur ekonomis kendaraan yaitu selama 7 tahun, dengan tahun rencana 2017-2013. Analisis selama umur rencana pada penelitian ini menggunakan proyeksi nilai inflasi Kota Denpasar sebesar 0,34\% (Badan Pusat Statistik, 2015). Adapun skenario investasi pada penelitian ini adalah dengan pengadaan angkutan wisata yang bergerak secara reguler maupun charter ke objek wisata yang ada di Kota Denpasar. Angkutan wisata direncanakan bergerak ke objek wisata yang dipaketkan sesuai dengan daya tarik objek wisata, adapun paket wisata tersebut adalah :

- Paket wisata alam dan budaya

- Paket wisata city tour

- Paket 10 objek wisata (Full Paket)

\section{HASIL DAN PEMBAHASAN}

\section{Potensi Kunjungan Wisatawan}

Jumlah calon penumpang yang dimaksud dalam penilitian ini adalah jumlah kunjungan yang terdapat pada objek wisata di Kota Denpasar yang dilalui oleh trayek angkutan wisata yang telah direncanakan. Adapun data yang didapat adalah data kunjungan tahun 2009-2013 yang didapat dari Dinas Pariwisata Kota Denpasar. Dengan kenaikan rata-rata $2.6 \%$ maka didapat jumlah kunjungan pada tahun 2017.

Tabel 1 Potensi Demand Angkutan Pariwisata Kota Denpasar

\begin{tabular}{|c|c|c|c|}
\hline No & Objek Wisata & $\begin{array}{c}\text { Jumlah } \\
\text { Kunjungan } \\
\text { per Tahun } \\
240 \text { hr (Org) }\end{array}$ & $\begin{array}{c}\text { Jumlah } \\
\text { Kunjungan } \\
\text { Rata-Rata } \\
\text { Harian } \\
\text { (Org) } \\
\end{array}$ \\
\hline 1 & $\begin{array}{ll}\text { Museum lukis } \\
\text { sidik jari }\end{array}$ & 448 & 2 \\
\hline 2 & Museum Bali & 29.049 & 121 \\
\hline 3 & Taman Budaya & 9.425 & 39 \\
\hline 4 & Pulau Serangan & 96.627 & 403 \\
\hline 5 & $\begin{array}{l}\text { Prasasti } \\
\text { Blanjong }\end{array}$ & 393 & 2 \\
\hline 6 & $\begin{array}{l}\text { Pasar } \\
\text { Kumbasari }\end{array}$ & 14.702 & 61 \\
\hline 7 & Pasar Badung & 20.384 & 85 \\
\hline 8 & $\begin{array}{l}\text { Desa Budaya } \\
\text { Kertalangu }\end{array}$ & 34.854 & 145 \\
\hline 9 & $\begin{array}{l}\text { Monumen } \\
\text { Perjuangan } \\
\text { Rakyat Bali }\end{array}$ & 144.340 & 601 \\
\hline 10 & Mangrove & 4.296 & 18 \\
\hline \multicolumn{2}{|c|}{ Jumlah } & 354.518 & 1.477 \\
\hline
\end{tabular}

Sumber : Hasil Analisis, 2015

Potensi demand pada penelitian ini dengan menggunakan estimasi wisatawan yang mau menggunakan layanan angkutan wisata rencana sebesar $30 \%$ dari kunjungan total pada. Untuk jumlah potensi demand 10 objek wisata sebesar 443 orang, untuk potensi demand wisata city tour 273 orang, untuk wisata alam dan budaya 170 orang.

\section{Rute Pelayanan Angkutan Wisata}

Adapun pemilihan objek wisata didasari oleh jumlah kunjungan terbanyak dari setiap objek wisata yang ada di Kota Denpasar. Rute pelayanan angkutan wisata dalam penelitian ini adalah sebagai berikut :

1. Rute yang melayani perjalanan objek wisata yang meliputi : Prasasti Blanjong, Pulau Serangan, Balai Pengelolaan Hutan Mangrove, Desa Budaya Kertalangu, Taman Budaya Art Centre, Museum Lukisan Sidik Jari, Monumen Bajra Sandhi, Pasar Kumbasari, Pasar Badung, Museum Bali. Jarak tempuh 50,40km dengan kecepatan rata-rata kendaraan $20 \mathrm{~km} / \mathrm{jam}$ didapat waktu tempuh per roundtrip 195.56 menit.

2. Rute yang melayani perjalanan wisata ke objek wisata dalam kota yang meliputi : Taman Budaya Art Centre, Museum Lukisan Sidik Jari, Monumen Bajra Sandhi, Pasar Kumbasari, Pasar Badung, Museum Bali. Jarak tempuh $25.80 \mathrm{~km}$ dengan kecepatan rata-rata kendaraan $20 \mathrm{~km} / \mathrm{jam}$ didapat waktu tempuh per roundtrip 119.2 menit.

3. Rute yang melayani wisatawan yang ingin mengunjungi objek wisata alam dan budaya di Kota Denpasar yang meliputi Pulau Serangan, Balai Pengelolaan Hutan Mangrove, Desa Budaya Kertalangu. Jarak tempuh $27,40 \mathrm{~km}$ dengan kecepatan rata-rata kendaraan $20 \mathrm{~km} / \mathrm{jam}$ didapat waktu tempuh per roundtrip 88.25 menit.

\section{Analisis Sistem Operasional Angkutan Wisata}

Adapun alternatif sistem operasional angkutan wisata pada penelitian ini sebagai berikut:

1. Alternatif kendaraan

- Menggunakan kendaraan jenis minibus, dengan kapasitas angkut kendaraan dalam melayani rute adalah 17 penumpang

- Menggunakan kendaraan jenis bus tipe sedang, dengan kapasitas angkut kendaraan dalam melayani rute adalah 35 penumpang. Proporsi penumpang yaitu 20 duduk dan 15 berdiri

2. Alternatif Operasional Angkutan

- Angkutan wisata beroperasional dengan bergerak secara rutin dalam trayek selama waktu operasional (ada/ tidak ada penumpang)

- Angkutan wisata beroperasional atau bergerak apabila hanya ada penumpang saja (model charter)

3. Alternatif Tarif Angkutan Wisata 
- Tidak dipungut biaya (asumsi gratis)

- Asumsi dipungut biaya

4. Alternatif Paket Pariwisata

- Paket 10 objek wisata Kota Denpasar

- Paket city tour

- Paket wisata alam dan budaya

\section{Perencanaan Angkutan Wisata (Reguler 10 Objek Wisata)}

Dalam penelitian ini, perencanaan angkutan wisata Kota Denpasar menggunakan 2 jenis angkutan yakni bus sedang dan minibus. Terdapat 10 objek wisata yang akan dilalui oleh angkutan wisata yang bergerak secara regular selama waktu operasional dari pukul 09.00 wita sampai dengan pukul 17.00 wita.

a. Waktu sirkulasi :

$$
\begin{aligned}
\mathrm{CT}_{\mathrm{ABA}}= & \left(\mathrm{T}_{\mathrm{AB}}+\mathrm{T}_{\mathrm{BA}}\right)+\left(\sigma_{\mathrm{AB}}^{2}+\sigma_{\mathrm{BA}}^{2}\right)+\left(\mathrm{T}_{\mathrm{TA}}\right. \\
& \left.+\mathrm{T}_{\mathrm{TB}}\right) \\
\mathrm{CT}_{\mathrm{ABA}}= & (132)+(5 \% \times 132)^{2}+(2 \times 10) \\
\mathrm{CT}_{\mathrm{ABA}}=132+(43,56)+(20) & 132.56 \text { menit }
\end{aligned}
$$

b. Waktu antara $(\mathrm{H})$ diasumsikan 30 menit.

c. Jumlah kendaraan per waktu sirkulasi $(\mathrm{K})$ :

$$
\begin{aligned}
\mathrm{K} & =\frac{C T_{A B A}}{H x f A} \\
f \mathrm{~A} & =\text { faktor ketersediaan kendaraan } \\
\mathrm{K} & =\frac{195.56}{30 x 100 \%} \\
& =6.52 \text { unit } \sim 7 \text { unit kendaran }
\end{aligned}
$$

Jadi perencanaan jumlah armada sebesar 7 unit kendaraan. Adapun perencanaan jumlah kendaraan disesuaikan dengan tingkat isian kendaraan. Jumlah kendaraan akan bertambah apabila tingkat isian/ load factor lebih dari $100 \%$

\section{Perencanaan Angkutan Wisata Reguler Wisata Alam}

Dalam penelitian ini, perencanaan angkutan wisata paket regular wisata alam menggunakan 2 jenis angkutan yakni bus sedang dan minibus. Angkutan wisata bergerak secara regular melayani wisatawan yang akan berkunjung ke objek wisata alam dan budaya seperti desa budaya kertalangu, pulau serangan dan juga mangrove. Angkutan pariwisata bergerak secara regular selama waktu operasional dari pukul 09.00 wita sampai dengan pukul 17.00 wita.

$$
\begin{aligned}
& \text { a. Waktu sirkulasi : } \\
& \mathrm{CT}_{\mathrm{ABA}}=\left(\mathrm{T}_{\mathrm{AB}}+\mathrm{T}_{\mathrm{BA}}\right)+\left(\sigma_{\mathrm{AB}}^{2}+\sigma_{\mathrm{BA}}{ }^{2}\right)+\left(\mathrm{T}_{\mathrm{TA}}\right. \\
& \left.+\mathrm{T}_{\mathrm{TB}}\right) \\
& \mathrm{CT}_{\mathrm{ABA}}=(70)+(5 \% \times 70)^{2}+(2 \times 3) \\
& \mathrm{CT}_{\mathrm{ABA}}=88.25 \text { menit }
\end{aligned}
$$

b. Waktu antara $(\mathrm{H})$ diasumsikan 30 menit.

c. Jumlah kendaraan per waktu sirkulasi $(\mathrm{K})$ :

$$
\begin{aligned}
\mathrm{K} & =\frac{C T_{A B A}}{H x f A} \\
f \mathrm{~A} & =\text { faktor ketersediaan kendaraan } \\
\mathrm{K} & =\frac{88.25}{30 x 100 \%)} \\
& =2.94 \text { unit } \sim 3 \text { unit kendaran }
\end{aligned}
$$

\section{Perencanaan Angkutan Wisata Reguler City Tour}

Dalam penelitian ini, perencanaan angkutan wisata paket regular city tour menggunakan 2 jenis angkutan yakni bus sedang dan minibus. Angkutan wisata bergerak secara regular melayani wisatawan yang akan berkunjung ke objek wisata dalam Kota Denpasar. Objek wisata yang akan dilayani adalah : Museum Lukis Sidik Jari, Museum Bali, Taman Budaya, Monumen Perjuangan Rakyat Bali, Prasasti Blanjong, Pasar Kumbasari, Pasar Badung. Angkutan pariwisata bergerak secara regular selama waktu operasional dari pukul 09.00 wita sampai dengan pukul 17.00 wita.

a. Waktu sirkulasi :

$$
\begin{aligned}
\mathrm{CT}_{\mathrm{ABA}=} & \left(\mathrm{T}_{\mathrm{AB}}+\mathrm{T}_{\mathrm{BA}}\right)+\left(\sigma_{\mathrm{AB}}^{2}+\sigma_{\mathrm{BA}}^{2}\right)+\left(\mathrm{T}_{\mathrm{TA}}\right. \\
& \left.+\mathrm{T}_{\mathrm{TB}}\right) \\
\mathrm{CT}_{\mathrm{ABA}}= & (87)+(5 \% \times 87)^{2}+(2 \times 7) \\
\mathrm{CT}_{\mathrm{ABA}}= & 119.92 \text { menit }
\end{aligned}
$$

b. Waktu antara $(\mathrm{H})$ diasumsikan 30 menit.

c. Jumlah kendaraan per waktu sirkulasi $(\mathrm{K})$ :

$$
\begin{aligned}
\mathrm{K} & =\frac{C T_{A B A}}{H x f A} \\
f \mathrm{~A} & =\text { faktor ketersediaan kendaraan } \\
\mathrm{K} & =\frac{119.92}{30 \times 100 \%} \\
& =3.99 \text { unit } \sim 4 \text { unit kendaran }
\end{aligned}
$$

\section{Perencanaan Angkutan Wisata Charter City Tour}

Dalam penelitian ini, di rencanakan angkutan pariwisata baik bus maupun minibus dapat disewakan selama 5,5 jam untuk melakukan paket perjalanan city tour (objek wisata dalam Kota Denpasar). Objek wisata yang akan dilayani adalah : Museum Lukis Sidik Jari, Museum Bali, Taman Budaya, Monumen Perjuangan Rakyat Bali, Prasasti Blanjong, Pasar Kumbasari, Pasar Badung.

a. Waktu sirkulasi :

$$
\begin{aligned}
\mathrm{CT}_{\mathrm{ABA}}= & \left(\mathrm{T}_{\mathrm{AB}}+\mathrm{T}_{\mathrm{BA}}\right)+\left(\sigma_{\mathrm{AB}}{ }^{2}+\sigma_{\mathrm{BA}}{ }^{2}\right)+\left(\mathrm{T}_{\mathrm{TA}}\right. \\
& \left.+\mathrm{T}_{\mathrm{TB}}\right) \\
\mathrm{CT}_{\mathrm{ABA}}= & 330 \text { menit }
\end{aligned}
$$

b. Waktu antara $(\mathrm{H})$ diasumsikan 30 menit.

c. Jumlah wisatawan $=(30 \% \times$ 911 $)=273$ orang

Kapasitas /seat kendaraan $=35$ seat (bus sedang) ; 17 seat (minibus)

Jumlah kendaraan yang dibutuhkan : 


$$
\begin{aligned}
\text { Bus sedang } & =\frac{273}{35} \\
& =7.8 \sim 8 \text { unit kendaran } \\
\text { Minibus } & =\frac{273}{17} \\
& =16.05 \sim 16 \text { unit kendaran }
\end{aligned}
$$

\section{Perencanaan Angkutan Wisata Charter Wisata Alam}

Dalam penelitian ini, di rencanakan angkutan pariwisata baik bus maupun minibus dapat disewakan selama 4.5 jam untuk melakukan paket perjalanan wisata alam dan budaya. Objek wisata yang akan dilayani adalah: Desa Budaya Kertalangu, Pulau Serangan, Hutan Mangrove.

a. Waktu sirkulasi :

$$
\begin{aligned}
\mathrm{CT}_{\mathrm{ABA}=} & \left(\mathrm{T}_{\mathrm{AB}}+\mathrm{T}_{\mathrm{BA}}\right)+\left(\sigma_{\mathrm{AB}}^{2}+\sigma_{\mathrm{BA}}{ }^{2}\right)+\left(\mathrm{T}_{\mathrm{TA}}\right. \\
& \left.+\mathrm{T}_{\mathrm{TB}}\right) \\
\mathrm{CT}_{\mathrm{ABA}}= & (45)+(5 \% \mathrm{x} 45)^{2}+(30 \times 7) \\
\mathrm{CT}_{\mathrm{ABA}}= & 330 \text { menit }
\end{aligned}
$$

b. Waktu antara $(\mathrm{H})$ diasumsikan 30 menit.

c. Jumlah wisatawan $=(30 \% \times 566)=170$ orang

Kapasitas /seat kendaraan $=35$ seat (bus sedang) ; 17 seat (minibus)

Jumlah kendaraan yang dibutuhkan :

$$
\begin{aligned}
\text { Bus sedang } & =\frac{170}{35} \\
& =4.86 \sim 5 \text { unit kendaran } \\
\text { Minibus } & =\frac{170}{17} \\
& =10 \text { unit kendaran }
\end{aligned}
$$

\section{SIMPULAN DAN SARAN}

\section{Simpulan}

1. Berdasarkan analisis yang dilakukan untuk mengetahui potensi demand dan rute angkutan wisata Kota Denpasar dapat disimpulkan:

a. Jumlah wisatawan yang berkunjung ke Kota Denpasar selama tahun 2013 adalah sebanyak 438.576 orang dan diperkirakan menjadi 485.998 orang pada tahun 2017 dengan kenaikan rata-rata $2.6 \%$. Adapun kunjungan tersebut adalah data yang didapat dari Dinas Pariwisata. Data kunjungan tersebut adalah data kunjungan ke 10 objek wisata yang ada di Kota Denpasar dengan jumlah kunjungan terbanyak tiap tahunnya. Objek wisata yang mendapat kunjungan tertinggi adalah : Prasasti Blanjong, Pulau Serangan, Balai Pengelolaan Hutan Mangrove, Desa Budaya Kertalangu, Taman Budaya Art Centre, Museum Lukisan Sidik
Jari, Monumen Bajra Sandhi, Pasar Kumbasari, Pasar Badung, Museum Bali. Dari total kunjungan wisatawan merupakan kunjungan wisatawan lokal maupun domestik, maupun kunjungan yang non wisata. Adapun potensi demand pada penelitian ini dengan menggunakan estimasi kunjungan untuk paket wisata regular ke 10 objek wisata adalah $30 \%$ dari data total wisatawan.

b. Rute angkutan wisata pada penelitian ini disesuaikan dengan lokasi 10 objek wisata yang menjadi objek kunjungan tertinggi wisatawan Kota Denpasar. Adapun objek yang dilayani oleh angkutan wisata adalah : Prasasti Blanjong, Pulau Serangan, Balai Pengelolaan Hutan Mangrove, Desa Budaya Kertalangu, Taman Budaya Art Centre, Museum Lukisan Sidik Jari, Monumen Bajra Sandhi, Pasar Kumbasari, Pasar Badung, Museum Bali.

2. Berdasarkan analisis yang telah dilakukan, dapat disimpulkan sistem karakteristik operasional angkutan wisata yang dapat diterapkan di kota Denpasar adalah sebagai berikut :

a. Angkutan wisata yang digunakan adalah Isuzu NQR 71 Medium Bus dengan kapasitas 35 penumpang dan Minibus Mitsubishi FE 71 Long+Karoseri dengan kapasitas 17 penumpang.

b. Berdasarkan potensi penumpang, diperoleh alternatif paket wisata, antara lain : Paket wisata regular 10 objek wisata, paket regular city tour, paket regular wisata alam dan budaya, paket charter city tour, dan paket charter wisata alam dan budaya.

c. Waktu pelayanan yang di desain untuk angkutan wisata di Kota Denpasar dibagi berdasarkan rute pelayanan dan disesuaikan dengan jam kunjungan. Untuk angkutan yang melayani 10 objek wisata secara regular beroperasi dari pukul 09.00 wita sampai dengan pukul 17.00 wita. Angkutan yang melayani paket regular wisata alam beroperasi dari pukul 09.00 wita sampai dengan pukul 17.00 wita. Angkutan wisata yang melayani paket regular city tour akan beroperasi dari pukul 09.00 wita sampai dengan pukul 17.00 wita. Untuk angkutan charter city tour beroperasi selama 5.5jam dan angkutan untuk charter wisata alam adalah 4,5 jam.

d. Pelayanan angkutan wisata dikhususkan bagi wisatawan baik lokal maupun domestik yang ingin mengunjungi objek wisata yang ada di Kota Denpasar. Pelayanan angkutan wisata juga di lengkapi oleh seorang guide tour yang selama perjalanan akan menjelaskan 
secara singkat mengenai objek wisata yang akan dikunjungi.

\section{DAFTAR PUSTAKA}

Anonim. 2003. Keputusan Menteri Perhubungan Penyelenggaraan Angkutan Orang Di Jalan Dengan Kendaraan Umum No.35. Jakarta.

Anonim. 1979. Peraturan Pemerintah No.24 Tentang Penyerahan Sebagian Urusan Pemerintahan Dalam Bidang Kepariwisataan Kepada Daerah Tingkat I. Jakarta.

Anonim. 2009. Undang-Undang No.10 Tentang Kepariwisataan. Jakarta.

Anonim. 2009. Undang-Undang No.22 Tentang lalu Lintas dan Angkutan Jalan. Jakarta.

Badan Pusat Statistik. 2015. Proyeksi Nilai Inflasi Kota Denpasar September 2015. Denpasar.

Departemen Perhubungan. 1996. Penentuan Jumlah Armada dan Penjadwalan. Jakarta : Badan Pendidikan dan Latihan Perhubungan Pusat Pendidikan dan Latihan Perhubungan Darat.

Pemerintah Kota Denpasar.2013.Data Pariwisata Kota Denpasar.Denpasar. 